\title{
Do étnico ao pan-étnico: negociando e performatizando identidades indígenas
}

From the ethnic to the pan-ethnic: negotiating and performing indigenous identities

Terezinha Machado MAHER

(Universidade Estadual de Campinas - Unicamp)

RESUMO

O objetivo deste texto é refletir, com base na teoria dos atos de fala proposta por Austin em 1962, sobre os modos como um grupo de professores indígenas da Amazônia Ocidental, mais precisamente do Estado do Acre, performatizam suas identidades em interações transculturais. Interessa-me aqui focalizar, sobretudo, os modos como esses professores constroem, discursivamente, não apenas suas identidades étnicas, mas, também, seu pertencimento a um grupo que, multiétnico, compartilha um projeto político comum.

Palavras-chave: Performatividade; professores indigenas; identidade étnica; identidade pan-étnica. 


\section{ABSTRACT}

Drawing from the speech-act theory proposed by Austin in 1962, this paper aims at reflecting upon the ways a group of indigenous teachers located in Occidental Amazonia, more specifically in the State of Acre, Brazil, performatively constitute their identities in transcultural interactions. It is my intention to focus particularly on the way these teachers discursively construct, not only their ethnic identities, but their affiliation to a multiethnic group who shares a common political project as well.

Key-words: Performativity; indigenous teachers; ethnic identity; panethnic identity.

\section{Introdução}

A teoria dos atos de fala proposta por Austin (1962) tem sido para mim crucial na tarefa de desvendar algumas dos sentidos e algumas das práticas que circulam no universo indígena acreano, universo esse no qual adentrei, pela primeira vez, no início da década de 90 . Venho, desde essa época, atuando como docente e consultora do setor de educação da Comissão Pró-Índio do Acre (CPI-Ac), uma organização não governamental e laica, que se ocupa com a formação de pesquisadores e professores indígenas de diferentes etnias (Kaxinawa/Huni Kui, Yawanawa, Shãwãdawa, Katukina, Jaminawa, Asheninka e Manchineri) nesse estado da federação.

A compreensão de que "os enunciados que produzimos referem-se fundamentalmente a certas ações que performatizamos na linguagem ou através do seu uso" (Rajagopalan, 2012: 85) é o que vem me permitindo melhor entender, por exemplo, alguns aspectos da "etiqueta interacional" frequentemente observados pelos professores indígenas que venho observando (Cf.: Maher, 1998, 2006), os sentidos por eles atribuídos a certas práticas discursivas tradicionais (Cf.: Maher, 1996, 2010), bem como o lugar e o peso da linguagem na performatização de suas identidades (Cf.: Maher, 1996, 2012).

No espaço deste texto, pretendo discorrer, apoiada em dados empíricos, sobre os modos como membros dos povos indígenas contemporâneos tanto reivindicam para si próprios, em seus discursos, uma identidade genérica, essencializada, quanto tentam dela escapar, numa 
negociação permanente com seus outros e com eles mesmos (Silva, 2005: 7). Nesse percurso, parto do pressuposto que a constituição da identidade só pode ser entendida se a pensarmos em termos de um constructo sociocultural e histórico por natureza, e por isso mesmo, essencialmente político, ideológico e em constante mutação. Tomo como certo, também aqui, que a identidade não é algo que nos é dado $a$ priori, mas que é no uso da linguagem que ela é construída e projetada: a identidade não é algo que somos e, sim, algo que fazemos, é efeito de discursos, é performativa. ${ }^{1}$

\section{Definindo o "ser índio"}

Quem são os índios brasileiros hoje? O que os marca e os define? Se considerarmos as contribuições da antropologia para respondermos a essas questões veremos que é problemático afirmar que grupos sociais, quaisquer que sejam eles, são formados por atributos dotados de uma essencialidade.

Desde Franz Boas (2010), a antropologia abandonou o uso de critérios raciais para definir e identificar diferentes coletividades humanas. Buscou-se, em um primeiro momento, substituir a noção de raça pela noção de cultura, acreditando-se que essa substituição seria suficiente para libertar a antropologia de explicações deterministas. Ao longo do séc. XX, contudo, o próprio conceito de cultura foi colocado em discussão pela antropologia, que passou a reconhecer que seu uso poderia se desdobrar em análises tão reducionistas quanto aquelas que se sustentavam em critérios raciais.

Segundo uma concepção essencialista de cultura, a somatória de traços culturais fixos definiriam um grupo étnico. Visto desta maneira, um índio seria aquele que usa arco e flecha, anda nu, enfeita-se com penas e urucum e fala uma língua indígena, se essas, por exemplo,

1. A noção de identidade como performatividade é creditada principalmente às contribuições de Judith Butler (2012[1990]). Inspirada na teoria dos atos de fala de Austin (1992) e nos conceitos derridarianos de iterabilidade e citacionalidade para pensar questões de gênero e sexo, a autora argumenta a favor de uma compreensão da identidade não como algo que ontologicamente "se é" e, sim, como algo que "nos tornamos". A esse respeito, ver também Silva (2000), Silva (2008) e Livia e Hall (2010). 
tivessem sido as dimensões eleitas pelo grupo étnico ao qual pertence como marcas irredutíveis de sua identidade. Tal concepção sugere uma percepção estática do fenômeno. Mas, as culturas são dinâmicas e estão, por isso mesmo, sujeitas a constantes alterações (Cf.: Cardoso de Oliveira, 1976, 2006; Carneiro da Cunha, 2009; Silva, 2005).

Além do fato de que traços culturais não são inalteráveis dado o caráter fluido da cultura, é preciso também questionar as próprias concepções que buscam definir grupos étnicos a partir do conceito de cultura. O conteúdo cultural não define uma etnia porque língua, religião, ornamentos, etc. são, como afirma Ribeiro (1970), atributos externos a ela, não suas características primárias. Ou, como deixa claro Carneiro da Cunha (1981, 2009), embora a cultura componha (de forma importante!) a etnicidade, ela não pode ser considerada um elemento definidor porque não é pressuposto, é, antes, produto, resultado, consequência da maneira de existir, de se organizar de um grupo étnico. Desse modo, "a cultura indígena não define o índio, mas, ao contrário, porque o indivíduo é índio, a cultura de que ele é portador é definida como sendo indígena" (Maher, 1996: 19).

Se rechaçamos raça e cultura como critérios para distinguir o índio, como, então, fazê-lo? Para Barth $(1969)^{2}$, grupos étnicos são tipos, formas de organização social cuja definição deve ser vista em termos de adscrição. Isto significa que a definição de um grupo étnico reside na identificação que seus membros fazem de si mesmos e de outros para se organizarem e interagirem socialmente: é índio, então, quem se define como tal e define seu interagente como não-índio. Por isso, afirma Barth (1969: 16), a identidade étnica envolve o estabelecimento de fronteiras de identificação entre o "nós" e o "eles". 3

A identidade étnica do índio, vista desta maneira, é, então, um fenômeno emergente, no sentido de que ela emerge, surge mesmo como resultado de interações transculturais entre este e membros de outros grupos sociais e étnicos. Afirmar isso significa aceitar que a construção da identidade implica multifacetamento, já que o outro com

2. A origem da moderna teoria da identidade, do ponto de vista da antropologia, é creditada ao trabalho, publicado originalmente em 1969, do antropólogo interacionista norueguês Fredrik Barth. 
o qual interagimos não é sempre o mesmo, o tempo todo, em todas as situações sociais. Logo, a etnicidade não é fenômeno unitário que contenha em si qualquer essência definitória, mas é uma construção discursiva feita em múltiplas direções, direções estas muitas vezes contraditórias (Cf.: Hall,1998).

Tendo me posicionado quanto à etnicidade indígena é preciso apontar, no entanto, que, como já argumentei algumas vezes anteriormente (Cf.: Maher, 1996, 2006, 2012), vimos sendo "educados", em nosso país, a partir de um posicionamento ideológico que procura apagar as diferenças étnicas dos povos indígenas aqui lotadas com o intuito de torná-las menos visíveis em suas particularidades aos olhos da nação brasileira. Considerando que uma estratégia eficaz quando se quer dominar um grupo étnico é destituí-lo de qualquer singularidade (Cf.: Caleffi, 2003; Cardoso de Oliveira 2006), vimos, desde os primórdios da nossa História, procurando firmar a noção de índio genérico. Vai daí todos os membros dos povos indígenas que habitavam/habitam o território brasileiro terem sido/estarem sendo postos em uma mesma categoria e rotulados de "índios". Mas, o que se tem, em nosso país, são 220 povos indígenas distintos ${ }^{4}$, cada um deles com suas especificidades linguísticas, seus hábitos e crenças, seus modos específicos de estar no mundo. O que esses populações têm em comum - e quaisquer outras generalizações precisam ser feitas com muita parcimônia! - é o fato de todos elas serem de origem pré-colombiana e de terem sido vítimas de uma experiência traumática de contato com o "homem branco". Em tese, portanto, não existiria a coletividade "índios", em abstrato, no Brasil: existem 220 povos indígenas diferentes. No entanto, sabemos que a etnicidade está inscrita nos fatos históricos e, quando consideramos a História de contato dos povos indígenas lotados em território nacional, temos, portanto, que, necessariamente, inscrevê-la em um processo homogeneizante e criador de dominação, de subalternidade. Porque é neste processo mesmo, e no conflito que o constitui, que o "índio" tem que, como diz literalmente Brandão (1986: 55), "aprender às pressas o que finalmente é ser índio", essa nova identidade amalgamada, essencializada que lhe é imposta pelo invasor.

4. Embora a FUNAI estime o número de povos indígenas em 220 (ver http://www.funai. gov.br/), o ISA - Instituto Socioambiental calcula esse número em 241 (cf. http://pib.socioambiental.org/pt/c/no-brasil-atual/quem-sao/povos-indigenas). Ambos os sites foram acessados em 21/11/2013. 
E é então nesse jogo complexo entre a reafirmação de uma etnicidade e a construção de uma identidade genérica que podemos vislumbrar a complexa constituição da indianidade contemporânea, como espero ser capaz de demonstrar no que segue.

\section{Performatizando a identidade étnica}

Em minha longa convivência com professores indígenas do Acre, não foram poucas as ocasiões em que pude testemunhar performances identitárias por eles encenadas para resistir à dissolução de suas etnicidades. O episódio que descrevo a seguir é exemplar neste sentido.

Era abril de 1994 e um grupo de três professores indígenas acreanos - Llullu Manchineri, Ixã e Tenê Kaxinawá - permaneceram cinco dias em Campinas, São Paulo, período no qual fizeram uma visita a uma escola da cidade, como parte das atividades programadas para celebrar a "Semana do Índio". A programação para essa visita incluía uma "aula/palestra" para uma, então, turma de $5^{\text {a }}$ série do Ensino Fundamental. Essa atividade foi, sob minha supervisão, inicialmente planejada pelos professores indígenas em questão do seguinte modo: os dois professores Kaxinawá ensinariam aos alunos, utilizando como recurso metodológico o diálogo dramatizado, como cumprimentar em seu idioma, a língua Hãtcha Kui, e caberia a Llullu discorrer sobre aspectos da vida cotidiana em sua aldeia. Logo após as crianças terem entusiasmadamente praticado, com Ixã e Tenê, o diálogo escrito em Hãtcha Kui no quadro-negro, a professora responsável pela turma explicou que, em seguida, elas iriam aprender como "os índios" vivem em suas aldeias. LLullu dirigiu-se à frente da sala de aula e, muito incisivamente, enfatizou para os alunos que ele era membro de uma outra etnia, de outro povo indígena. Sem dizer mais nada, esse professor foi à lousa e escreveu o equivalente ao diálogo apresentado pelos dois professores Kaxinawá, na sua própria língua. E procedeu à pratica desse diálogo com os alunos, algo não previsto. Embora Lhullu estivesse representando os "índios do Acre" naquele evento, não lhe interessava ser visto como "índio genérico", falante de uma "língua indígena genérica", por aqueles alunos "brancos". E foi esse motivo pelo qual ele performatizou, muito assertivamente, que, diferentemente 
de Tenê e Ixã, era membro do povo indígena Manchineri, era falante da língua Manchineri.

É preciso deixar claro que, embora reasseverar suas identidades étnicas seja uma preocupação constante dos professores indígenas acreanos em suas interações interculturais, construções de uma identidade indígena genérica, como dito anteriormente, são também, por vezes, relevantes para esse grupo (Cf.: Maher, 1996, 2012). Isso porque

(...) a partir do final dos anos 1960, quando os movimentos sociais de afirmação de identidade começaram a eclodir, o ser índio passou a ser fonte de dignidade e de auto-valorização do "Nós tribal". Tal como no movimento negro norte-americano cunhou-se a expressão 'Black is beautiful!', no movimento indígena expressões equivalentes começaram a surgir! O reconhecimento da identidade indígena enquanto ser coletivo passou então a ser mais do que um direito político, mas um imperativo moral. (...) Pode-se dizer, com isso, que a ambiguidade histórica da categoria índio, enquanto termo identitário originalmente pejorativo, acabou por se desfazer no bojo dos movimentos indígenas libertários (Cardoso de Oliveira, 2006: 111).

\section{Performatizando a identidade pan-étnica}

Tem sido comum, nas práticas discursivas indígenas que venho podendo observar (Cf.: Maher, 1996), ouvir-se referências a "nós, índios": especificidades étnicas são muitas vezes empalidecidas, suspensas temporariamente, em prol da construção de uma identidade indígena pan-étnica, no intuito de se atender a interesses políticos comuns. ${ }^{5}$ De modo a poder convencer o leitor da veracidade desse argumento, recupero, no que segue, alguns trechos de uma interação bastante longa (de cerca de 40 minutos) por mim analisada anteriormente (Cf.: Maher, 2012). Essa interação refere-se ao relato oral de uma viagem internacional realizada por um professor indígena Jaminawa. Uma das agências financiadoras do projeto de Educação da CPI-Ac, o comitê norueguês da Rain Forest Foundation havia convidado um representante indígena e um não-indígena dessa entidade brasileira a participarem, na Noruega, de uma série de eventos de sua campanha anual de arrecadação de fundos, que é conduzida por estudantes do 
Ensino Médio daquele país. Dada a proximidade da viagem, o professor Júlio Jaminawa foi escolhido pela CPI-Ac para ir à Noruega por ser ele, à época, o professor indígena que mais rapidamente poderia se locomover até Rio Branco. Na sua volta, Júlio fez o relato dessa sua viagem para seus colegas que estavam na capital do Estado do Acre para participarem do seu XIII Curso de Formação Continuada para o Magistério Indígena. E é neste relato que o leitor poderá perceber, espero, a construção, pelos próprios professores indígenas, de uma faceta de suas identidades: a de índios pan-étnicos. ${ }^{6}$

Comecemos a análise, observando o que professor Júlio afirma logo no inicio de sua narrativa: ${ }^{7}$

(...) então, ai os pessoal norueguense queria que o índio mesmo participasse também desse projeto... o CPI fez o projeto e encaminhou pra Noruega... aí, as organização estudantil norueguense aprova o projeto para o índio... NÃO os índio tudo, pra NÓS professores que tamo querendo alfabetizar nossos aluno... que nós num queremo largar desse nosso estudo porque eu acho que a gente num é ainda aQUEle professor que dá pra ensinar na oitava série... na sétima, na sexta. E é por isso mesmo a gente precisamo desse recurso... bom, então, por isso mesmo eu fui escolhido... quer dizer, eu num fui escolhido pela comunidade, não, mas era eu que tava mais próximo... e então eu fui participar desse projeto... fui levar esse nosso interesse, levar essa nossa reivindicação de... dizer qual é o interesse dos índio, porQUE que nós precisa desse recurso... então foi mais pra isso, né? eu mosTREI o nosso interesse, quer dizer, eu num falei só o nome da minha comunidade, falei GEralmente nós...

Note-se que Júlio, nesse trecho, justifica o fato de ter sido ele o professor indígena escolhido para ir à Noruega representando o programa de educação ao qual está filiado: "eu num fui escolhido

6. De forma a poder observar o limite de espaço a mim reservado para este texto, os trechos aqui transcritos foram bastante editados. Essa narrativa pode ser encontrada transcrita em sua íntegra em Maher, 1996.

7. Na transcrição dos dados aqui analisados, foram observadas as seguintes convenções: maiúsculas para indicar ênfase; parênteses duplos para indicar comentário do transcritor; aspas para indicar discurso indireto; barra para indicar corte sintático; ponto de interrogação para indicar entoação ascendente; dois pontos para indicar alongamento de vogal; vírgula para indicar pausa de menos de dois segundos e reticências para indicar pausa de mais de dois segundos. 
pela comunidade, não, mas eu que tava mais próximo... e então eu fui participar desse projeto". Nessa sua primeira utilização do termo "comunidade", Júlio, diferentemente do que faz no final do trecho transcrito não está se referindo a nenhum aldeiamento Jaminawa: “... eu mosTREI o nosso interesse, quer dizer, não falei só o nome da minha comunidade, falei GEralmente nós...”. A comunidade perante a qual ele inicialmente se justifica é a comunidade formada pelos professores-índios do projeto da CPI-Ac. E qual é, exatamente, a natureza, a composição desta comunidade, deste "nós" a que Júlio se refere? Quais são, afinal, seus interesses? Essa é, evidentemente, uma comunidade de profissionais da educação interessados em conseguir fundos para garantir a continuidade de sua formação profissional. $\mathrm{O}$ interesse pedagógico do grupo é, definitivamente, um elo que une os membros dessa comunidade, mas não é o único. Vejamos o que Júlio afirma posteriormente:

(...) e num foi SÓ o Brasil que participou desse projeto... ((em tom didático)) quatro país participaram do projeto estudantil norueguense... quais foram? foi o Brasil, foi o Peru, Bolivia, Costa Rica... porque hoje não é só nosso pais... aquele que fica no Mercado Sul, como seja, a Argentina, a Bolivia, né? que é considerado como terceiro mundo... porque na Costa Rica também... eles foram massaCRAdo igualmente nós também... com quinhentos ano de luta que a gente continua... o indio querendo se mostrar, nosso povo sofrido... e eles fazem mesmo assim também... eles levaram aquele reivindicação... eles estão querendo melhorar também, tão querendo saIR também... como a gente TÁ QUERENdo também sair dessa... a gente tá querendo chegar lá... muitos/num é SÓ nós que luta... tem muitos outros lugares fora do Brasil, que é vizinho, também que tão querendo também o PRÓprio indio se organizar e... leVAR esse reivindicação do povo TAMbém massacrado igualmente nós... num é só o Brasil que não reconhece nós, né?... mas valeu, né?... valeu verem pessoalmente o indio, né?

Este trecho deixa claro a que outros interesses, além dos ganhos profissionais, Júlio Jaminawa se referia quando, no começo da interação, afirmou “.... eu mosTREI o nosso interesse, quer dizer, não falei só o nome da minha comunidade, falei GEralmente nós...”. Estes professores indígenas têm uma reivindicação comum por serem membros de povos que foram, historicamente, vencidos e que querem sair da situação adversa em que foram a partir daí colocados: "a gente 'TÁ 
QUERENdo também sair dessa... a gente ‘tá querendo chegar lá...”. "Lá" é na autodeterminação política, é na emancipação econômica e social. E o primeiro passo para que sua reivindicação seja ouvida é reverter o apagamento histórico: é se tornarem, todos, novamente, visíveis ("com quinhentos ano de luta que a gente continua... o índio querendo se mostrar"). E neste sentido a viagem de Júlio à Noruega foi um sucesso: "Mas valeu, né?... Valeu verem pessoalmente o índio, né?". Não um índio Jaminawa, observem, mas "o" índio, ou seja, todo aquele que, independentemente da etnia e da nacionalidade, foi vitimado pelo contato: afinal, as probabilidades de conseguir a visibilidade almejada são maiores quanto maior for o número de reivindicantes.

Os professores-índios presentes sabiam disto. Eles sabiam que os avanços sociais, políticos e econômicos que os povos indígenas do Acre vêm conseguindo nas últimas duas décadas não foram apenas decorrência das lutas isoladas de cada um desses povos. Os ganhos obtidos por um dado povo indígena, com relação, por exemplo, à posse da terra, rapidamente, ecoa, incentiva e favorece lutas semelhantes de outras etnias. Essas lutas comuns possibilitaram que, apoiados pelas entidades indigenistas do estado, eles se articulassem e estabelecessem alianças entre si. O fortalecimento dessas alianças é, neste processo de "globalização" indígena, extremamente importante. Por isso, mais interessante do que apontar diferenças étnicas é, muitas vezes, ressaltar o interesse em comum. Os membros dessa comunidade não se caracterizam fundamentalmente, nesta interação, pelas suas diferenças. Ao contrário, percebe-se um esforço para minimizá-las, como pode ser deduzido também no trecho da fala de Júlio abaixo: ${ }^{8}$

(...) e nesse dia a gente palestrou em DUas escola... e em CAda escola tinha quatro grupo de aluno... ou era três?... aí quando terminava, a gente voltava pra essa cidade de Bering... mas aí foi muito bom, a gente se deu muito bem... eu também entrava assim pra mostrar como era nossa cultura, né? eu tinha levado urucum, eu pintava meu rosto... e aí eles me fizeram tantas várias perguntas... "por que que o índio USA esse tipo de... urucum?", eu digo, "não, isso é porque... isso é da nossa cultura porque a gente, a gente usamo urucum/ mas também num é SÓ esse negócio de pintar, também tem outra questão... é que o índio tem um modo de viver diferente". 
Chamou-me, de imediato, a atenção, na análise preliminar desta interação, o fato de que, nesse trecho, Júlio, por duas vezes, ter dito "nossa cultura". Minha primeira hipótese foi a de que um impedimento gramatical explicasse a não flexão do possessivo nesse sintagma. Esta hipótese não se sustentou, no entanto. Observe-se que logo no início de sua narrativa, esse professor Jaminawa diz "nossos aluno" ("Não os índio tudo, pra NÓS, professores que tamo querendo alfabetizar nossos aluno...”). A gramática da variedade do português falado por Júlio Jaminawa permite a flexão do pronome possessivo. Portanto, ele poderia ter dito "nossas cultura", mas não disse. Por quê? Se o sintagma não flexionado tivesse aparecido só na resposta à pergunta feita pelos europeus nada de significativo poderia ser dito aqui. Nas representações dos "brancos", os índios da Amazônia fazem parte de um só povo, daí o apagamento das diferenças culturais ("Por que que o índio USA esse tipo de... urucum?"). Júlio, sabendo disto e não lhe interessando desfazer o equívoco, teria respondido "Não, isso é porque... isso é nossa cultura porque que a gente, a gente usamo urucum". Esta explicação, contudo, não se aplica ao que foi dito anteriormente: "Eu também entrava assim prá mostrar como era nossa cultura, né?". Aí Júlio não está ventrilocando, reproduzindo, em discurso direto, o que foi dito a "branco" nenhum. É ele quem está falando e está falando para os outros professores indígenas, para professores indígenas de outras etnias. Lançando mão de um elemento comum a todos do grupo - o urucum - Júlio faz um amálgama, uma síntese cultural e cria uma cultura indígena que é “nossa”, é de todos os índios, é pan-étnica. É verdade que todos os povos indígenas do Acre se pintam com o urucum, mas a frequência de uso desse corante varia muito de etnia para etnia (os Manchineri o fazem raramente, os Jaminawa com certa frequência, os Ashenika quase que cotidianamente). Também o significado místico, curativo atribuído a esta pintura corporal varia, dependendo do grupo e das crenças que dão sustentação a seus rituais. Essas diferenças, no entanto, são postas de lado, ignoradas, para possibilitar a emergência do "índio portador de uma cultura genérica" e é esse o motivo pelo qual Júlio tem permissão do grupo que o ouve para fazer a "síntese cultural" que fez. Enfatizar diferenças étnicas não é interessante para Júlio na maior parte desta interação, muito pelo contrário, como também atesta o que ele afirma no trecho abaixo: 
(...) “você só fala só português?”... eles ((os noruegueses)) perguntavam... eu digo, "NÃO... eu num falo muito bem português, eu falo muito bem a MInha língua. .”.. “então fala prá mim aí, deixa eu ver... ”... eu digo "eu FA::lo... ”... "e tu sabe cantar na tua língua?”... eu digo "eu SEI..." e cantava pra eles... ((rindo)) aí me emprestaram um violão... ((risos de todos)) tinha vez que eu fazia era show o tempo inteiro ((gargalhadas de todos))... Eu cantei bastante... canta ::va...canta::va ((tentando se recompor)) mas foi um sucesso pra NÓS AQUI... não só pra mim...

Júlio afirma ter falado e cantado em sua língua materna - o idioma Jaminawa -, mas para que a ênfase colocada em "MInha língua...", utilizada para estabelecer oposição ao português, não seja mal interpretada por seus interlocutores, Júlio, rapidamente, esclarece "foi um sucesso pra NÓS AQUI... não só pra mim”. O professor Jaminawa não é, na interação em foco, o único interagente, entretanto, a performatizar uma indianidade genérica, como veremos a seguir.

Eu estava presente a este evento e, para mim, ficou patente que o riso fácil de todos traduzia a alegria e o orgulho de terem sido representados na Europa por alguém tão carismático, tão bem articulado, tão assertivo e talentoso como Júlio Jaminawa. Em um dado momento, Ibã, um professor Kaxinawá, não se contentando com o relato, quis visualizar a cena que os europeus haviam presenciado:

Ibã: ((rindo)) por exemplo, né?... aqui nós somo família de Noruega, né?... tu 'tá chegando aí prá se apresentar... ((risos)) VAI, faz aí, faz pra gente ver...

Júlio: mas tá me faltando/mas sem o violão, né?... aquela música que eu fiz/porque eu tenho minha música... ((rindo)) porque nós semo artista também agora, né? ((risos))... e eu ia cantando e tocando... e cantando na minha língua... Eu cantei aquela minha música que eu sei cantar...

Ibã: então VAI, CANta...

Para Ibã Kaxinawa, não era relevante que a música tivesse sido cantada na língua dos Jaminawa, e não em seu próprio idioma, o Hãtcha Kui. Ele coloca em suspenso, neste momento, tanto a sua identidade étnica quanto a de Júlio, em atenção ao interesse maior e comum de alcançar a tão desejada visibilidade. O importante era que o "branco" 
- e não um "branco" qualquer, diga-se de passagem, um "branco" de um país de primeiro mundo... - vira e ouvira um "índio", qualquer que fosse sua etnia. Para quem, até há pouco tempo, nem sequer existia em sua própria terra natal, ${ }^{9}$ esta não é uma questão banal. Esta é uma questão política fundamental. Temos aqui, então, o uso do português como língua franca permitindo que uma identidade indígena panétnica se sobreponha, por vontade política do sujeito, à sua etnicidade. Curioso, o branco apagou as diferenças étnicas para apagar o índio da História. Hoje, o índio, por vezes, esconde diferenças étnicas para nela se reinserir...

\section{Considerações finais}

Procurei demonstrar, neste texto, que performatizar, em suas interações transculturais, dois pólos identificatórios - índio étnico e índio genérico - é, hoje, para o grupo de professores indígenas aqui focalizados uma necessidade. Por vezes, é preciso fazer valer suas identidades étnicas, como fez Llullu Manchineri em sua visita à escola de Campinas. Mas, por outras, é preciso descolorir, empalidecer essas mesmas especificidades, em prol da construção discursiva de uma outra faceta de suas identidades na qual eles, porque comprometidos com uma causa política comum, se fazem simplesmente "índios". A linguagem, também para esses professores, é, portanto, o lugar onde podem exercer uma dualidade identitária, dualidade essa que atesta o multifacetamento na constituição do sujeito que, como tão bem coloca Silva (2008:25), "não é senhor de si, mas alguém que vive na corda bamba, tendo de fazer escolhas continuamente no desdobrar temporal e dialógico de sua ação no mundo".

Recebido em janeiro de 2014

Aprovado em janeiro de 2015

E-mail: tecamaher@gmail.com

9. Até a década de 70, explicam os antropólogos Marcelo Iglesias e Terri de Aquino (1994), a existência de populações indígenas no estado do Acre era negada pelos órgãos governamentais e por importantes segmentos da sociedade local. Esses reconheciam apenas populações "caboclas" nos seringais acreanos. 


\section{Referências bibliográficas}

Austin, John Langshaw. 1962. How to do things with words. Oxford: Clarendon Press.

BArth, Frederik. 1969. Ethnic Groups and Boundaries: The Social Organization of Cultural Difference (Org.). Boston: Little, Brown and Co.

BoAs, Franz. 2010. Antropologia Cultural. Tradução: Celso Castro. Rio de Janeiro: Jorge Zahar.

Brandão, Carlos Rodrigues. 1986. Identidade e Etnia - Construção da Pessoa e Resistência Cultural. São Paulo: Ed. Brasiliense.

Butler, Judith. 2012[1990]. Problemas de Gênero - Feminismo e Subversão da Identidade. Tradução: Renato Aguiar. $4^{\mathrm{a}}$ edição. Rio de Janeiro: Civilização Brasileira.

CAlefFr, Paula. 2003. O que é Ser Índio Hoje? A questão indígena na América Latina/Brasil no início do século XXI. In: SiDEKUM, Antônio (org.). Alteridade e Multiculturalismo. Ijuí: Editora Ijuí. pp. 175205.

CARdoso de Oliveira, Roberto. 1976. Identidade, Etnia e Estrutura Social. São Paulo: Pioneira.

2006. Caminhos da Identidade - Ensaios sobre Etnicidade e Multiculturalismo. São Paulo: Editora UNUSP; Brasília: Paralelo 15.

Carneiro da Cunha, Manuela. 1981. Critérios de Indianidade ou Lições de Antropofagia. Tempo e Presença, $\mathrm{n}^{\circ} 169$. 2009. Cultura com Aspas e Outros Ensaios. São Paulo: Cosac Naify.

Hall, Stuart. 1998. A Identidade Cultural na Pós-modernidade. Rio de Janeiro: DP\&A.

IgLesias, Marcelo Piedrafita \& Aquino, Terry Valle de. 1994. Processo de Regularização de Terras Indígenas e Organização Política dos Índios no Estado do Acre (1975-1994). Rio Branco, mimeo.

Livia, Anna \& Hall, Kira. 2010. "É uma menina!": a volta da performatividade à linguística. In: Ana Cristina Ostermann \& Beatriz Fontana (orgs.). Linguagem, gênero, sexualidade: clássicos traduzidos. São Paulo: Parábola. pp. 109-127.

MAHER, Terezinha Machado. 1996. Ser Professor Sendo Índio: Questões de Lingua(gem) e Identidade. Tese de Doutorado, Instituto de Estudos da Linguagem, UNICAMP (inédita).

. 1998. Sendo Índio em Português. In: Inês Signorini (org.). Aplicado. Campinas: Editora Mercado das Letras. pp. 115-138. 
2006. Formação de Professores Indígenas: uma discussão introdutória. In: Luís Donizeti Grupioni (org.). Formação de Professores Indígenas: repensando trajetórias. Brasília: MEC/ SECAD. pp. 11-38.

2010. Políticas Linguísticas e Políticas de Identidade: currículo e representações de professores indígenas na Amazônia Ocidental brasileira. Currículo sem Fronteiras 10(1): 33-48.

2012. "Índio" para estrangeiro ver: pan-etnicidade em contexto multicultural indígena. Revista Língua \& Literatura, FW, v. 14, n. 23, dez. pp. 97-122.

Rajagopalan, Kanavillil. 2012. Performativity and the claims of scientificity of modern linguistics. D.E.L.T.A. 28(1):85-103.

Riberro, Darcy. 1970. Os Índios e a Civilização - a Integração das Populações Indígenas no Brasil Moderno. Petrópolis: Vozes.

SiLva, Tomaz Tadeu. 2000. A produção social da identidade e da diferença. In: Tomaz Tadeu Silva (org.). Identidade e Diferença - a perspectiva dos Estudos Culturais. São Paulo: Editora Vozes. pp. 73-102.

SiLva, Rita de Cácia Oenning. 2005. A performance da cultura: identidade, cultura e política num tempo de globalização. Antropologia em Primeira Mão. Florianópolis: UFSC/Programa de Pós-Graduação em Antropologia Social, n. 78.

SiLva, Daniel do Nascimento. 2008. A questão da identidade em perspectiva pragmática. Rev. Brasileira de Linguística Aplicada 8(1):13-33. 